\title{
Humanização: transformar as práticas de saúde, radicalizando os princípios do SUS
}

Humanization: transforming healthcare practices and radicalizing the principles of SUS

Humanización: transformar las prácticas de salud radicalizando los principios del SUS

\section{O imperativo da transformação das práticas}

É motivo de grande prazer intelectual ser convidado a tecer considerações a partir de um texto produzido por Ruben Mattos (2009). Como de costume, o autor nos oferece um texto claro e pleno de proposições penetrantes, o que faz, do convite ao debate, um convite para copensar, para a produção de novas singularidades de pensamento a partir do plano de pensamento que nos apresenta. E este plano é traçado no exame das relações entre os "princípios do SUS e as questões de transformação das práticas de saúde". Contrasta dois documentos basilares produzidos pelo movimento da Reforma Sanitária, evidenciando um deslocamento do foco de lutas desse movimento, que vai "da questão democrática ao imperativo da mudança nas práticas de saúde no SUS".

\section{Transformação das práticas/transformação dos problemas}

Quaisquer que sejam as transformações que se façam necessárias em determinadas "práticas", elas sempre implicam, necessariamente, transformações correlatas nos modos como os "problemas" são reconhecidos e configurados por esse "campo de práticas". Meu postulado de base, aliás, é esse: não há transformação no "campo das práticas" que não seja, indissociavelmente, transformação no "campo problemático".

Tomemos a questão, tão bem apontada no texto, da "eficácia simbólica" da premissa de que a qualidade das práticas no setor privado é superior à do SUS. Não creio que haja muitas chances de se esvaziar a "eficácia simbólica" dessa premissa, perseverando na ideia comum de que os setores público e privado oferecem respostas aos mesmos "problemas de saúde". Ora, sabemos como essa perspectiva tem reservado uma posição sistematicamente desvantajosa para o SUS e suas práticas. Mas o fato é que, talvez, as práticas do SUS só possam mesmo vir a ser as melhores respostas para outros "problemas de saúde"! O que significa que, para o SUS, a imagem de uma "qualidade superior" passaria sempre, em grande medida, pela demonstração de que estes outros "problemas" são os melhores "problemas", isto é, pela demonstração de que o SUS oferece não apenas a melhor resposta, mas a resposta aos "problemas" mais interessantes, mais potentes, mais virtuosos...

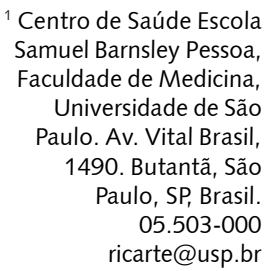




\section{Universalização excludente e outras ambivalências nas práticas}

Em suas análises, o autor nos mostra como a convivência do SUS com a chamada "saúde suplementar" (o fato do Sistema Único de Saúde não ser "o único sistema de saúde") "coloca questões importantes sobre os princípios da universalidade e, sobretudo, sobre o princípio da igualdade". Acompanho de perto estas análises, em especial quando descrevem as consequências dessa convivência como um processo de "universalização excludente". Considero a compreensão desse processo de suma importância para que possamos bem discernir as transformações das práticas que se fazem necessárias. Há, inclusive, várias outras expressões dessa "universalização excludente" que precisam ser reconhecidas e examinadas. Nestes diferentes "casos", um traço comum - que é sempre o elemento que ameaça a sustentabilidade dos princípios do SUS: o atravessamento por concepções "privatistas" da saúde.

Por isso, cabe se perguntar: qual a sustentabilidade dos "valores pelos quais temos lutado", quando se garante (às vezes, judicialmente) "a universalidade e a igualdade de acesso" (através do "sistema público") a práticas que são intrinsecamente excludentes? Haveria limite (e como seria definido) para o investimento "público" nesse tipo de práticas? E se essas perguntas cabem, é porque há, de fato, uma concepção de saúde como "bem privado" que, no limite, corrói toda possibilidade de se fazer da saúde um "bem comum"!

É preciso sublinhar, antes de se passar adiante, que as diferenças entre essas duas concepções não se referem apenas a qualidades extrínsecas (como, por exemplo, ser "plano de saúde privado" ou SUS, ser "mercadoria" ou "dever do Estado"), mas se inscrevem e se expressam no coração das práticas! Precisaremos, cada vez mais, compreender o funcionamento das práticas, desenvolver nossa capacidade de lê-las e, num esforço analítico, atingir seu vórtice produtivo, seu núcleo de produção de valores, de socialidade, de subjetividade, de governamentalidade...

Quando um "mandato judicial" obriga um gestor municipal a empenhar metade do orçamento para custear o direito de acesso a um raro e caro tratamento de um único "cidadão-usuário", temos uma interpretação (um uso) do princípio da "universalidade do direito à saúde" que, sem dúvida, traz ameaças à ideia de saúde como um "bem comum", pela forte tensão que estabelece com o princípio da igualdade.

Ora, mas não é essa mesma tensão "excludente" que se faz presente, quando se dá, por exemplo, uma "universalização" pra valer do acesso a programas de prevenção? E mesmo que seja apenas àqueles "baseados em evidências"! De qualquer modo, como se sabe, quase todos baseados no controle de fatores de risco; quase todos, portanto, fundados numa lógica de proteção e de consumo individuais. Ou seja, quase todos facilmente capturáveis pelas dinâmicas imaginárias destas duas lógicas fortemente individualistas: a securitária e a consumista... O que constitui, afinal, um breve resumo das características intrinsecamente "privatistas" destas práticas de prevenção.

Com certeza, também fazem parte (como efeitos ou sintomas) desse "caso" de "universalização excludente", os graves problemas de sobrecarga de trabalho (e, assim mesmo, de constante déficit de oferta de serviços em relação à demanda) que vêm sendo enfrentados pelas equipes de atenção primária, em várias partes do mundo, mas, de modo mais intenso, justamente onde estes serviços estariam mais bem estruturados, procurando dar mais ênfase às ações de prevenção (Ostbye et al., 2005; Yarnall et al., 2003). Em outras palavras, suas equipes não têm conseguido dar conta da tarefa que vem sendo proposta e, nesse contexto, a escolha entre "atender os doentes" e "investir na prevenção" tem sido, efetivamente, vivida como um dilema. Para alguns autores (Gérvas et al., 2008; Heath, 2007), a excessiva "ênfase na prevenção" seria mesmo uma ameaça ao princípio da "equidade": "desvia recursos dos pobres e doentes para os ricos e sadios, e dos velhos com enfermidades várias aos jovens cheios de saúde, o que resulta muito pouco equitativo" (Gérvas, Pérez Fernández, 2007).

Em todos esses "casos", o que se sobressai é que, sempre que os princípios da universalidade e da integralidade acabam por ferir o da igualdade, isso se deve a algum tipo de funcionamento "excludente" que é intrínseco à prática de saúde em questão. 


\section{Integralidade: sofrimento e felicidade na transformação das práticas}

Ruben Mattos postula que o princípio da integralidade teria o potencial de pautar a transformação das práticas do SUS e, assim, abrir a "perspectiva de reversão radical da imagem simbólica de qualidade superior da saúde suplementar". Retoma o sentido de integralidade que está expresso no texto constitucional ("o SUS deve se pautar pelo atendimento integral, com prioridade para as atividades preventivas sem prejuízo das atividades assistenciais"), mas, sobretudo, para ressaltar que o esforço para evitar o sofrimento não pode se dar em prejuízo da capacidade de resposta ao sofrimento manifesto risco que, como vimos acima, está colocado de um modo bastante concreto na prática atual. De fato, o autor propõe mesmo que o sofrimento seja a categoria-chave para se pensar a transformação das práticas, numa linha de argumentação que não está muito distante da dos autores acima citados (especialmente lona Heath, 2007).

Sou sensível ao seu argumento de que "há uma diferença fundamental entre as atividades preventivas e as atividades assistenciais: (estas, que) se fazem diante de um sofrimento manifesto, (e aquelas, que) se fazem antecipando-se ao sofrimento". Compreendo a transcendência de se propor que as transformações das práticas se orientem pela ampliação de sua capacidade de responder, antes de tudo, ao sofrimento manifesto. Ainda mais, quando não é infrequente que as próprias práticas sejam a causa do sofrimento. Entendo bem o seu sentido e concordo que essa referência ao sofrimento mereça obviamente destaque no horizonte problemático das práticas de saúde.

Contudo, não estou seguro de que a referência ao sofrimento, por si só, seja capaz de pautar a transformação das práticas que se faz necessária, aquela em que os "valores pelos quais temos lutado" sejam sustentáveis, porque não creio que esse foco no sofrimento represente uma mudança substancial no modo como os "problemas de saúde" já têm, afinal, se configurado nas práticas. Acho que as práticas que se fazem necessárias (que não contradigam, mas afirmem os princípios do SUS) precisam, efetivamente, se orientar por outros "problemas", melhores, mais interessantes...

Assim, eu poderia dizer que, entre as atividades preventivas e assistenciais, há uma diferença fundamental, mas há também uma continuidade fundamental: seja antecipando-se, seja fazendo frente a sua forma manifesta, o horizonte de ambas as práticas parece ser um só: uma sociedade sem sofrimento, da "saúde perfeita" e do "risco zero" (Fugelli, 2006; Sfez, 1996). Pouco importa se esse horizonte é imaginário, pois tanto mais ele se faz o pivô da eficácia simbólica de um certo ideal das práticas - preenchido pela "saúde suplementar"!

Indiscutivelmente, "o sofrimento é algo inerente à vida humana, como o é o cuidado e os esforços para reduzir e evitar". Não creio, entretanto, que "o conhecimento médico que [...] organiza atualmente as práticas de cuidado" se caracterize primordialmente por "conhecer os sofrimentos atribuíveis às doenças". Exagerando um pouco, quase acharia mais preciso afirmar o inverso: conhece muito mais as doenças do que os sofrimentos que poderiam ser a ela atribuídos, a ponto de esta prática ter dificuldades em reconhecer e lidar com sofrimentos aos quais não corresponda uma patologia médica. É claro que se há um conhecimento da patologia é porque, antes, houve um reconhecimento, na clínica, de um "estreitamento no modo concreto de andar a vida", como nos ensinou Canguilhem (1984). No entanto, é exatamente porque o conhecimento da patologia, no limite, se dissociou do sofrimento manifesto, que se pode, inclusive, evitá-lo pelas práticas de prevenção. Argumento que estamos diante de práticas que se destacam por um profundo conhecimento da "história natural das doenças" e um conhecimento cada vez mais raso das bases afetivas do sofrimento.

Concordo com Ruben quando afirma que os "sucessos práticos" só podem ser medidos pelas "consequências da aplicação dos dispositivos técnicos no modo de andar a vida concreta do sujeito que sofre, ou que pode vir a sofrer em conseqüência da doença". Mas não estou seguro de que uma noção de "sucesso prático" que se oriente fundamentalmente pela resposta dada ao sofrimento seja aquela que se oriente pelo melhor "problema", do ponto de vista de sua potência, de sua propensão a produzir as respostas mais virtuosas. Nesse sentido, ainda me aparece amplamente mais potente uma 
idéia de "sucesso prático" que se oriente pelos "projetos de felicidade", como nos propõe José Ricardo Ayres (2001). Mais ainda, num contexto em que há um verdadeiro "imperativo de construção de um 'projeto de doença' como estratégia engendrada pela população para inclusão na lógica do serviço e para que o sofrimento possa ser acolhido [...]" (Dalbello-Araújo, 2005, p.175).

Insistindo na tese de que a transformação das práticas que teria as melhores chances de promover a reversão radical da imagem simbólica da qualidade do SUS, seria aquela que se orientasse por "problemas" inteiramente outros (sempre melhores!), proponho que a "qualidade superior" do SUS se afirme pela maior capacidade, de suas práticas e instituições, de se orientarem pelos "projetos de felicidade" dos indivíduos e dos grupos; de apoiarem diferentes "modos de andar a vida" ("normais" ou "patológicos"); de contribuírem, sempre, para o aumento do nosso poder de afetarmos e sermos afetados, em suma, de contribuírem para o aumento da potência da vida ${ }^{2}$. Estou convencido de que esse modo de configurar o "campo problemático" é aquele mais propenso a produzir práticas capazes de sustentar "os valores pelos quais temos lutado"... Pelo menos, daqueles valores pelos quais realmente valha a pena lutar!

Assim, para aceitar a proposição do autor de que o princípio da integralidade possa "nos oferecer uma chave para reconceitualizar a qualidade que aspiramos", precisaria reivindicar um novo sentido para a noção de cuidado integral, definido não tanto pela "articulação entre propostas voltadas a responder ao sofrimento manifesto e ao sofrimento antecipado", e muito mais por integrar as preocupações com a saúde (enquanto conceito referido à vida orgânica, ao corpo orgânico) com as preocupações com a Grande Saúde (enquanto conceito referido à vida não-orgânica, ao Corpo sem Órgãos), indissociavelmente. Porque estou convencido de que apenas uma reconfiguração do "campo problemático" que integrasse, de maneira indissociável, a atenção ao corpo orgânico (homeostático) com a atenção ao corpo intensivo (fora do equilíbrio), corpo produtor de valores intensivos (baseados em conhecimentos e afetos), seria capaz de engendrar uma reinvenção das nossas práticas que realmente pudesse valer a pena!

Uma política de humanização que, obviamente, mais nada guardasse da eiva "filantropista" ou de "correção moral" dos agentes que se desviaram da "boa prática", só poderia ter esse sentido: o de reinventar as práticas (os núcleos de produção de valores) para que uma radicalização dos princípios do SUS seja possível e sustentável, para que se possa efetivamente afirmar o SUS como uma política pública e a saúde como um "bem comum".
2 Entendendo vida tanto em sua acepção biológica, a vida do ser vivo (vida orgânica), quanto em seu sentido afetivo, a vida como experiência da intensidade da vida ( vida não orgânica).

\section{Referências}

AYRES, J.R.C.M. Sujeito, intersubjetividade e práticas de saúde. Cienc. Saude Colet., v.6, n.1, p.63-72, 2001.

CANGUILHEM, G. Le normal et le pathologique. Paris: PUF, 1984.

DALBELLO-ARAÚJO, M. O cotidiano de uma equipe do Programa de Saúde da Família: um olhar genealógico sobre o controle social. 2005. Tese (Doutorado em Psicologia) - Universidade Federal do Espírito Santo, Vitória. 2005.

FUGELLI, P. The Zero-vision: potential side effects of communicating health perfection and zero risk. Patient Educ. Couns., n.60, p.267-71, 2006.

GÉRVAS, J.; PÉREZ FERNÁNDEZ, M. Los limites de la prevención clínica. AMF, v.3, n.6, p. $352-60,2007$. 
GÉRVAS, J.; STARFIELD, B.; HEATH, I. Is clinical prevention better than cure? Lancet, n.372, p.1997-9, 2008.

HEATH, I. In deference of a National Sickness Service. BMJ, n.334, p.19, 2007.

MATTOS, R.A. Princípios do Sistema Único de Saúde (SUS) e a humanização das práticas de saúde. Interface - Comunic., Saude, Educ., p.771-80, 2009.

OSTBYE, T. et al. Is there time for management of patients with chronic diseases in primary care? Ann. Fam. Med., n.3, p.209-14, 2005.

SFEZ, L. A saúde perfeita: crítica de uma nova utopia. São Paulo: Loyola, 1996.

YARNALL, K.S.K. et al. Primary care: is there enough time for prevention? Am. J. Public Health, n.93, p.645-9, 2003.

Recebido em 15/05/09. Aprovado em 16/06/09 